\title{
Visualization service for grid-oriented applications of natural disasters
}

\author{
E. Pajorova, L. Hluchy \& L. Halada \\ Institute of Informatics, Slovak Academy of Sciences, Slovakia
}

\begin{abstract}
Every year, forest fires cause enormous damage to vegetation and fauna, environment and property and bind significant human resources. Particularly in national parks and nature reservations, unique areas of high degree of protection can be devastated by fire. For instance, during the destructive forest fire in the Slovak Paradise National Park (Slovakia) in 1976, very unique vegetation was destroyed in the Kysel' Gorge, where the recovery into the former state will take 200 years [1]. Until now (thirty years after the fire), this locality is closed for tourists because of the vast damage. The topic of a lot of projects is how to prevent such disasters. Our research institute is oriented on GRID computing. A lot of international projects oriented on natural disasters utilise grid computing and within grid solution raises requirement of visualization service for presentation of the intermediate or final results. The basic aim of our research is to create a visual service for modelling and 3D rendering of natural disasters, before fire, flood and landslides. Changing the input data of fires spread used to generate new outputs very quickly. Grid computing on a lot of Clusters and 3D visualisation service can allow new scenes of fire spread. Outputs are used for far adjustment to liquidation fires or floods and landslides.
\end{abstract}

Keywords: forest fire, GRID applications, natural disasters, visualization service.

\section{Introduction}

3D visualization service for animation of natural disasters should integrate visualization requests of any kind of application solved in our institute and before solved in international projects oriented on environmental problems. The natural disasters like fires and floods become subject of science in research 
institutions more and more often. Many applications from this area are using different kinds of simulation tools, which are producing output data for displaying the results of the computation. The purpose of the visualize service is to model and display results of various simulations of natural disasters such as fire spread in time, fire intensity, flood velocity, landslide activity etc. Such service requires unified standards like integration of input data formats and especially creation of unified visualization tool.

This paper is describing such a visualization service developed and tested in our institute, create a 3D visualization service for GRID oriented natural disasters applications. The purpose of $3 \mathrm{D}$ viz. service is to model and display intermediate or final results of various simulations of natural disasters like fire spread in time, its intensity and erosion or floods in time or landslides as well. The output of the service is various scenes of terrain by different simulation outputs. Output of the service can also be the files representing the virtual reality of natural disaster and also files, which are generated as input for VR-Systems. 3D service was tested with outputs from applications, which were solved in our institute and also by data from applications of the MEDIGRID project [13].

Particular demonstrations in this article are from fires in Marseille industrial port in the southeast. The second is from a large fire in the Krompla region [1], which is part of the Slovensky Raj. Flood demonstrations are from Povazie, the region around the river $\mathrm{Vah}$. The root of visual service is to create a modelling tool. A modelling tool consists of modules, which were necessary to create. Each module is a UNIX shell script in which is prepared the start of the executables. The modules are divided into three groups according to what kind of output 3D models the group is generating. The functionality of each group is described by appropriate schema.

\section{Generating 3D models}

- Models of terrain or model of environment.

- Models of simulations.

- Virtual reality models of terrain and simulation (fire spread, flood, landslide etc.).

\subsection{Models of terrain or model of environment}

The first group of modules developed by us in the 3D viz. service is used for the creation of 3D terrain models and environment models. For 3D models of this type the following modules have been created: CONVERTOR, TERRAIN, IVFIX and CONVERTTOWRL. Examples: (see Figs. 1 and 2).

Advances in computers and information technologies in the last decades stimulate the development of various useful program systems for Natural Disasters (ND) fighting. Particularly, disasters behavior predicting systems can be directly used for specific purposes of fire management, or they can be included in more complex decision support systems (e.g. pre-suppression planning systems). For example for FIRE - behavior predicting systems are 


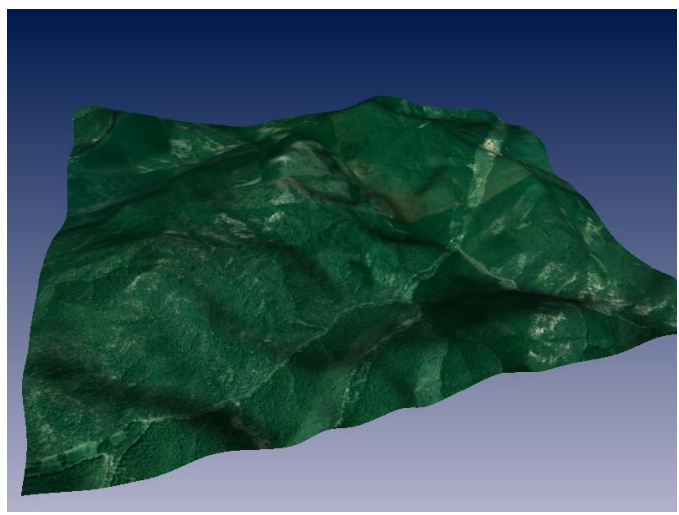

Figure 1: $\quad$ Krompla region - terrain model.

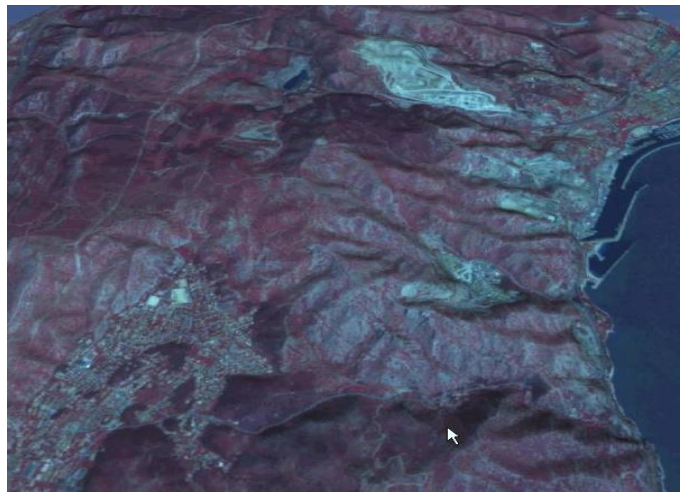

Figure 2: $\quad$ Marseille industrial port - terrain model.

capable to simulate the forest fire front growth after the fire detection [9]. They describe not only the spatial and temporal behavior of forest fires (fire spreading rate and direction), but can quantify and often even display various fire characteristics (e.g. fire intensity, flame length, etc.), which can be useful for the purposes of fire effects analysis. They can be used for simulation of various fire scenarios in a certain region under different conditions to test the fire management response for the fire event (prevention). Most suppression decision support systems are based on fire behavior prediction and make it possible to test the effectiveness of different types of suppression strategies and tactics, taking into account the existing fire fighting infrastructure and specific conditions that affect the fire fighting (e.g. location of water sources, Fire Fighting Headquarters, road network, etc.). The fire behavior models are also used for the reconstruction of previous forest fire events (post-suppression). Such simulations are particularly useful to understand the circumstances that lead to human incidents due to fire fighting [4-6]. Fire behavior predicting systems can also be useful for operational training. Currently, in general, little use of the forest fire decision support systems in operational fire management in the European Union 
is a great challenge for scientific and development activities within current fire research [2]. Although a forest fire hazard in Slovakia is relatively small compared to other forest land countries, the fires do occur and they are feared for their potential resulting damages. Moreover, during the forest fire in the Slovak Paradise National Park in 2000, the fire had threatened people's lives and nature reserve in the national park. During this forest fire there were various opinions on how to fight the fire in relation to protection of nature and ground attack tactics available. The speed and efficiency of the fire suppression were also very important. Unfortunately, there was no fire simulation model available for the support of strategic fire fighting decisions. On the basis of this experience, the use of a forest fire simulator appeared to be reasonable. From this reason, some national institutions stimulated the investigation of computer-aided forest fire growth simulation and visualization.

From the existing systems available, the FARSITE fire simulator was used for simulation of forest fires. The tests performed confirmed that this simulation system could be used under Central European conditions [8] (comp. also [3]). However, there are some factors, which complicate this effort. Primarily, the topography of the terrain can be very complicated and some phenomena (for instance the so-called chimney effect) could be described to a certain extent only. Moreover, the standard NFFL [7] fuels are not adapted to Central European conditions, therefore new fuel models for those territories must be defined. The precise estimation of fuel parameters is very demanding with respect to a vegetation complexity on a small research area and a diversity due to large elevation differences and protected character of the considerable portion of Slovak mountains. Therefore, an original methodology for the classification of forest vegetation in Slovakia and new fuel models were developed for selected localities $[8,10,11]$. Then reconstruction of the forest fire in the National Park Slovak Paradise in 2000 and analysis of the cause as to why people were trapped by the fire ( 6 people lost their lives) was carried out [8]. This paper presents our program module, which allows a dynamic $3 \mathrm{D}$ version of the forest fire simulation on real topography covered by "virtual forest". It is based on the output of FARSITE's fire spread simulation and it is developed for the purpose of 3D virtual reality of forest fire simulation. The described module is used for visualization of results of the reconstruction of the mentioned forest fire.

\subsection{Models of simulations}

The second group of modules in the Modelling tool is designed to generate Models of simulations. The following modules were created: CONVERTER, CLASSIFIER, COLOR SOTER, TIME SORTER and VIRTUAL SORTER and GENERATORS for static or for dynamic outputs. Our tool sorts these points according to the time and place, red faces for fire, blue faces for flood and brown faces for landslide. It starts from the point with the lowest time until the last one with the highest time. Input data for the second part of the Visualization tool are output data from simulators in different formats. Module CONVERTER converts them to singular format. Than data can input to CLASSIFIER module. CLASSIFIER sorts data and exports them to COLOR sorter and TIME sorter 
and some of them which are used for Virtual models to VIRTUAL sorter. Data from sorters input to GENERATORS. Generators are producing simulation models. Generator for static outputs produce Static models. Generator for dynamic outputs produce Dynamic models. Final visualization consists of terrain model and some simulation models. For example visualization of fire spread in time (see fig. 5) consists of TERRAIN.wrl and Fire spread.wrl files. Flood in time consists of TERRAIN.wrl and Flood.wrl files. Intensity of fire can be displayed statically.Outputs examples: see fig. 3 .

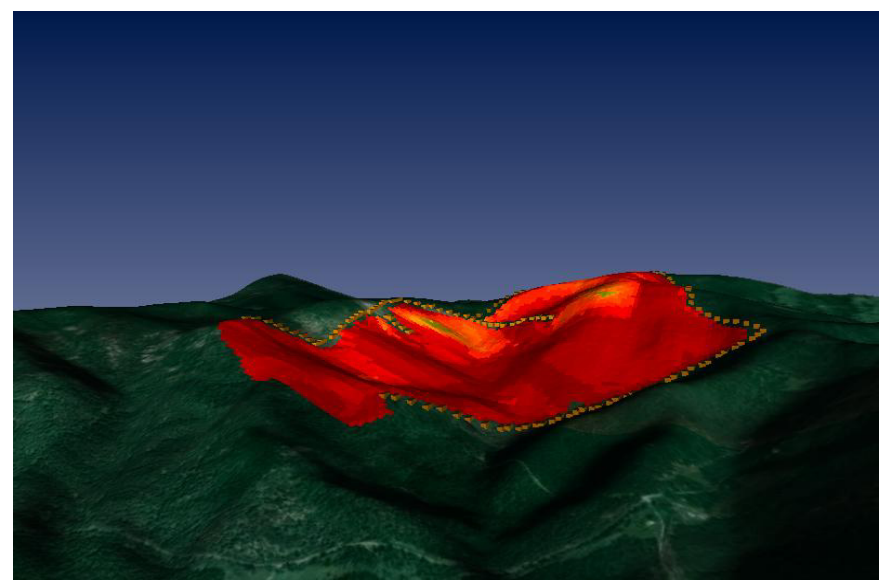

Figure 3: $\quad$ Forest fire model of simulation.

\subsection{Virtual reality models}

The third group of modules is designed to generate models suitable for virtual reality applications. The following modules were created: DATA SORTER, VIRTUAL TERRAIN SORTER, VIRTUAL SIMULATION SORTER and several GENERATORS. Process of creation. Outputs from Virtual sorter together with Special data for Virtual models are exported to DATA SORTER. It sorts the data and exports them into VIRTUAL TERRAIN SORTER or VIRTUAL SIMULATION SORTER. Data from sorters are input to GENERATORS. They are producing a lot of virtual models like for example virtual terrain or forest, virtual buildings, virtual fire, or virtual flood. To create virtual models, the visualization tool needs Special data for Virtual models which can be variable. For example for generating virtual forest special data are Grown maps, or for generating some buildings they are Project documentation etc. The following example demonstrates using part of the Visualization tool for the creation of the Virtual forest fire. Firstly we created virtual forest from Grown maps which were provided to us by the forestry. For generation of virtual forest we used forest grown simulator Sibyla. This software was developed by the Forest faculty in Zvolen in Slovakia (See Fig. 4).

The Sibyla system is composed of ten modules. One of them is Forest GENERATOR Input data are values from Grown maps. There is included all 
required information for creating each quad of virtual forest. A huge database of textures included in Sybila enables us to create different looks of the forest (morning, day, evening, etc.). Then by using the Visualization tool the same terrain, which was firstly covered by ortophotomap is now covered by just prepared virtual forest (see Fig. 5). In the end red faces were replaced by virtual fire textures using Virtual fire generator module (see Figs. 6 and 7).

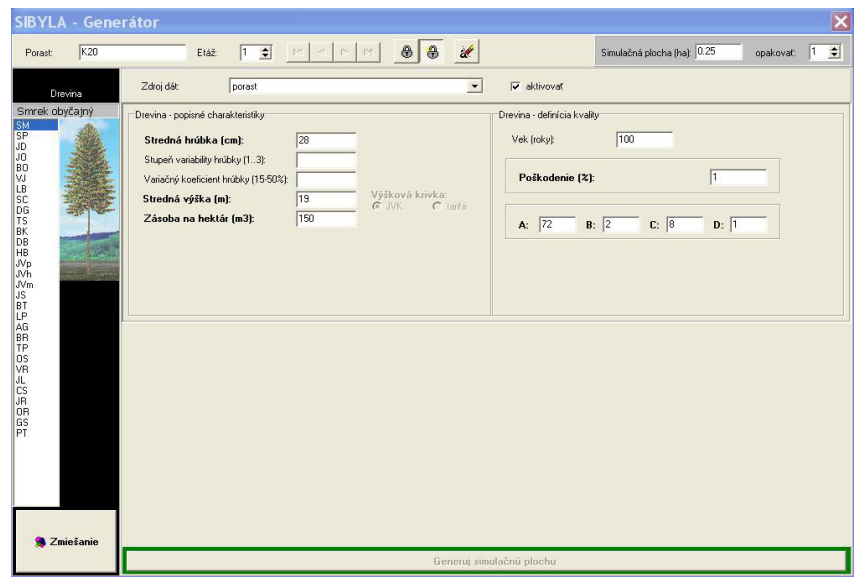

Figure 4: $\quad$ Sibyla forest generator.

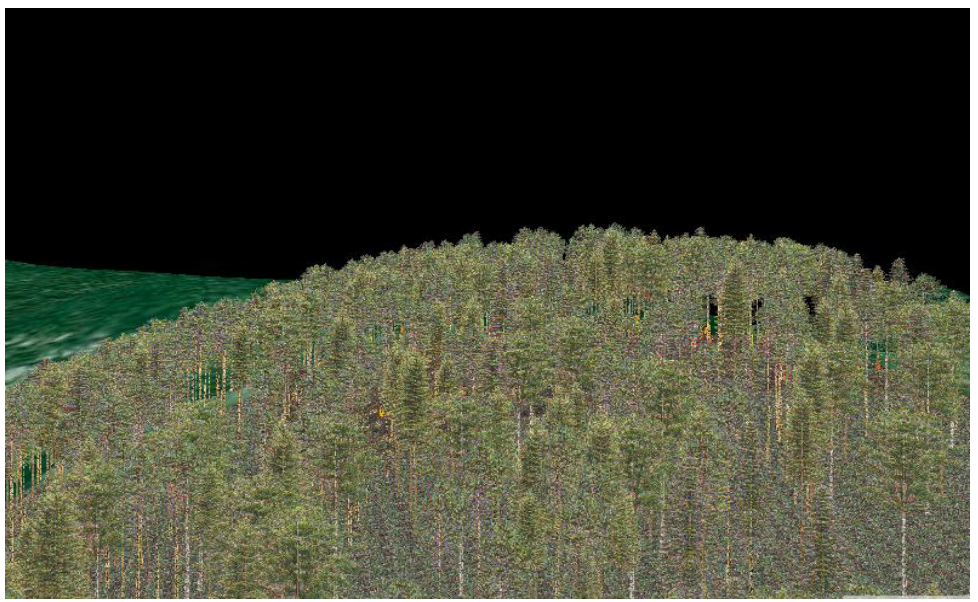

Figure 5: Virtual forest.

\section{Using the inVRs framework for collaborative visualization}

In order to provide a deep insight of the displayed datasets the inVRs framework is used for immersive visualization [20]. inVRs offer the possibility to render virtual environments in stereoscopic $3 \mathrm{D}$ graphics on a variety multi-display 


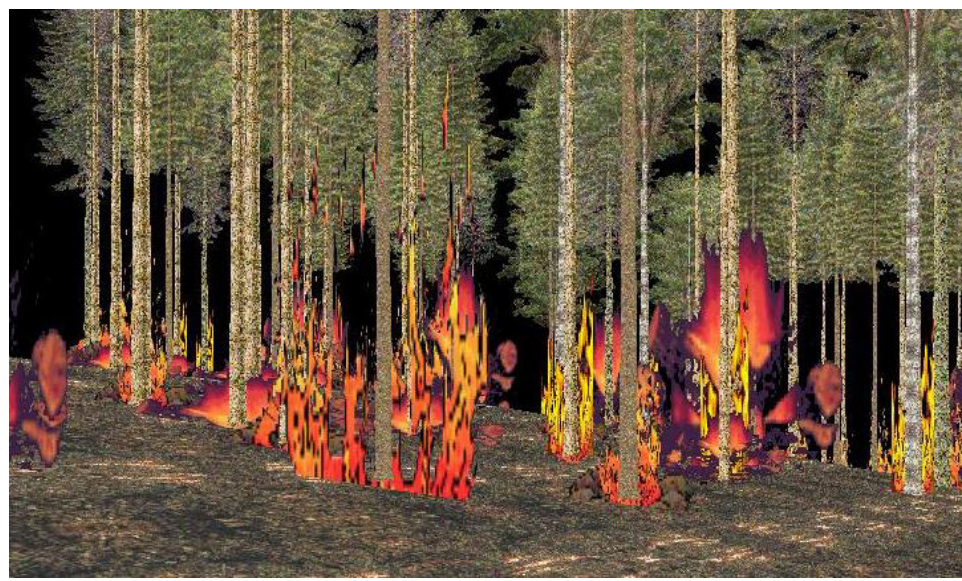

Figure 6: $\quad$ Virtual forest fire.

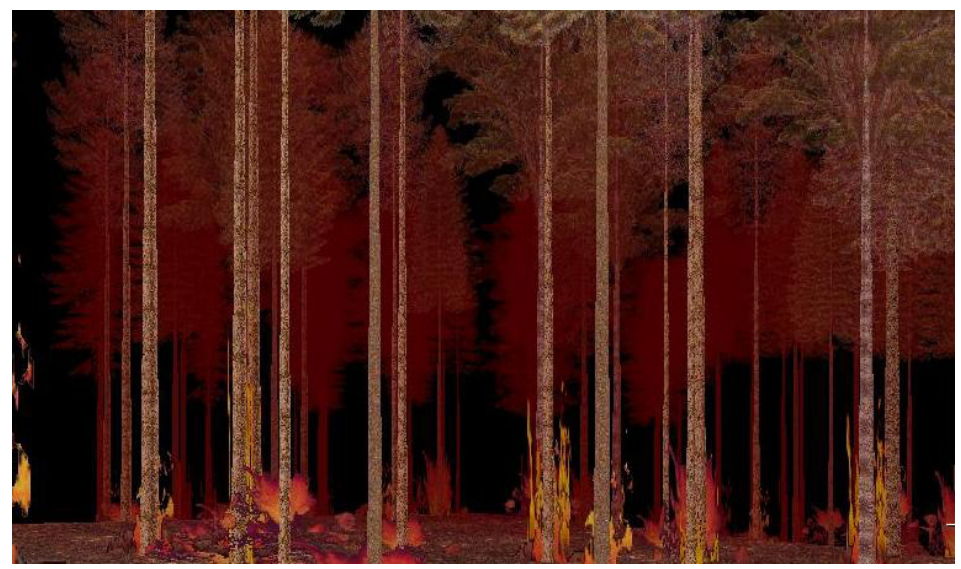

Figure 7: $\quad$ Forest fire during night.

output devices like the CAVE [5], curved screens or powerwall installations. The framework consists of independent modules for navigation, interaction and network communication, which are interconnected via its system core. Inside the core databases host objects and user information, like the datasets provided by pre-processing steps. To render the graphical display of inVRs applications OpenSG [21] is used as a scene graph. Users are able to navigate through the scenes depending on their chosen travel methodology and observe the scene as if they are standing in it. Different interaction methodologies can be chosen at the start up of the application. In the case of these visualizations switching of the different simulation steps is performed either automatically by starting an animation sequence or manually by pressing buttons to advance in the simulation. A valuable feature of the framework allows geographically dislocated users to collaboratively view and manipulate the datasets. To 
implement collaborative visualization the network module of the framework interconnects a set of clients in a peer-to-peer communication topology. The users are visualized by abstract avatars, which indicate the viewing orientation of the remote users.

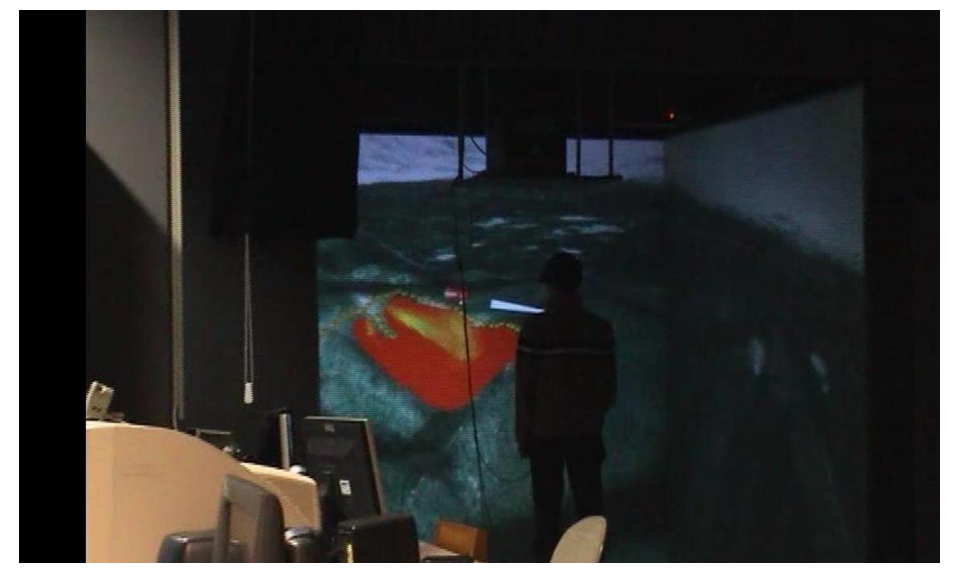

Figure 8: Visualization in CAVE.

\section{Visualization service}

The Visualization Service is a common job submission service used to run the modeling by scripts. The service will produce visualization outputs and make them available for the portal. The results of 3D visualizations require an additional VRML browser plug-in to be installed. Visual service was used and evaluated during the MEDIGRID project. In the future it can be incorporated in related projects of the domain of disasters management $[15,17]$.

\section{Conclusion}

Natural disasters simulation is a very complicated, challenging problem sensitive to the input data required. Therefore, intense research and development of sophisticated software systems and tools is extremely important for Natural disasters fighting management purposes. For example for Slovak forests, original methodology for forest vegetation classification and new fuel models have been developed and proper forest fire simulations related to the locality Krompla (National Park Slovak Paradise), where the large destructive fire appeared in 2000 and its reconstruction have been analyzed. These efforts induced the need of better auxiliary tools for 3D visualization of obtained simulation results and for animation of the forest fire spread. In this paper, new 3D visualization technique for real forest fire simulation and fire behavior and for flood and landslide modeling is described [18,19]. The importance is increasingly expanded for environmental problems [16]. 


\section{Acknowledgements}

This work was partially supported by Science and Technology Assistance Agency under the contract No. APVT-51-037902 and by the EU project MEDIGRID EU 6FP RTD GOCE-CT-2003-004044. And also is supported by RPEU project GRID_tools No. 0024-06 and VEGA project No. 2/7098/27.

\section{References}

[1] Juhas, F.: Forest Fire Slovak Paradise National Park (in Slovak), Report and Documentation of Department of Forest Fire Services, Spisska Nova Ves (2000).

[2] Xanthopoulos, G.: Forest fighting organization and approaches to the dispatch of forces in the European Union: results of the workshop survey, Proc. of the Int. Workshop on Improving Dispatching for Forest Fire Control (G. Xanthopoulos, ed.), Chania, Crete (2002), 143-153.

[3] Hille, M., Goldammer, J.G.: Dispatching and modelling of fires in Central European pine stands: New research and development approaches in Germany. Proc. of workshop.

[4] Finney, M.A.: FARSITE: Fire Area Simulator-Model, Development and Evaluation, Research paper RMRS-RP-4, USDA Forest Service (1998) Agronomic Institute of Chania, Crete, Greece (2001), 59-74.

[5] Viegas, D.X.: Surrounded by fire (in Portugal), Editorial Minerva, Coimbra (2004), $283 \mathrm{p}$.

[6] Viegas, D.X., Bibeiro, L.M., Silva, A.J. and Palheiro, P.: Analysis of S. Domingos accident, Proc. of the 4th Int. Conf. on Forest Fire Res. and Wildland Fire Safety, Luso, Portugal (2002) 18-23.

[7] Anderson, H.E.: Aids to determining fuel models for estimating fire behavior. USDA For. Serv. Gen. Tech. Rep. INT-122 (1982).

[8] Glasa, J., Halada, L.: Application of envelope theory for 2D fire front evolution. Int. Conf. on Forest Fire Research, Coimbra (2006).

[9] Richards, G.D.: An elliptical growth model of forest fire fronts and its numerical solution, Int. Journal for Num. Methods in Eng., 30 (1990), 1163-1179.

[10] Tuček, J., Schmidt, M., Celer, S.: Klasifikácia vegetačného krytu vo vysokohorských podmienkách z materialov DPZ s vysokým rozlíšením pri uplatnení apriorných poznatkov. Acta Facultatis Forestalis, vol. XLVII (2004), 89-102.

[11] Vida, T.: Metodika identifikácie a kvantifikácie palivových modelov pre simulovanie lesných požiarov, Diplom Work, Technical University in Zvolen, 2006.

[12] Viegas, D.X.: Surrounded by fire (in Portugal), Editorial Minerva, Coimbra (2004), $283 \mathrm{p}$.

[13] The EU project MEDIGRID EU 6FP RTD GOCE-CT-2003-004044.

[14] Hluchý, L., Habala, O., Nguyen, G., Šimo, B., Tran, V., Babík, M.: Grid Computing and Knowledge Management in EU RTD Projects of IISAS. In: 
Proc. of 1st International Workshop on Grid Computing for Complex Problems - GCCP 2005.

[15] Šimo, B., Ciglan, M., Slížik, P., Mališka, M., Hluchý, L.: Core services of heterogeneous distributed framework for multi-risk assessment of natural disasters. International Conference on Computational Science - ICCS 2006, May 28-31, 2006.

[16] Halada, L., Weisenpacher, P., Glasa, J.: Reconstruction of the forest fire propagation case when people were entrapped by fire. Forest Ecology and Management, Vol. 234S, 2006, pp. 116, ISSN 0378-1127.

[17] Peter Slížik, Eva Pjorová, Martin Mališka, Ladislav Hluchý: Geovizualizations in Medigrid. International Workshop on Environmental Applications and Distributed Computing. - EADC October 16-17, 2006 Bratislava, Slovakia.

[18] Halada, L., Weisenpacher, P., Glasa, J.: Reconstruction of the forest fire propagation case when people were entrapped by fire. Int. Conf. On Forest Fire Research, Coimbra (2006).

[19] Ján Glasa, Eva Pajorová, Ladislav Halada, Peter Weisenpacher: Animation of Forest Fire Simulation. International Workshop on Environmental applications and Distributed Computing. EADC October 16-17, 2006 Bratislava.

[20] Christoph Anthes and Jens Volkert: “inVRs - A Framework for Building Interactive Networked Virtual Reality Systems". In International Conference (HPCC), pp. 894-904, Munich, Germany, September 2006.

[21] Dirk Reiners: "OpenSG: A Scene Graph System for Flexible and Efficient Realtime Rendering for Virtual and Augmented Reality Applications”. PhD thesis, Technische Universität Darmstadt, Mai 2002. 